\title{
Correction to: Identifying crop yield gaps with site- and season-specific data-driven models of yield potential
}

\author{
Patrick Filippi $^{1}$ (D) Brett M. Whelan ${ }^{1} \cdot$ R. Willem Vervoort ${ }^{1} \cdot$ Thomas F. A. Bishop $^{1}$
}

Published online: 2 December 2021

(c) Springer Science+Business Media, LLC, part of Springer Nature 2021

\section{Correction to: Precision Agriculture https://doi.org/10.1007/s11119-021-09850-7}

The original version of this article unfortunately contained a mistake. Figures and Tables were not in sequential order and not placed nearby the citations in the originally published version.

The correct placement has been mentioned in this correction.

Table 2-should be placed under the heading "Comparison to "historical maximum yield' approach" in Methods section.

Table 3 and Figure 1—should be placed under the heading "Model validation" in Results section.

Figure 2 and Table 4-should be placed under the heading "Variable importance and model parameters" in Results section.

Figure 3 and Figure 4 should be placed under the heading "Yield gaps and potential yield across entire study area and study period" in Results section.

Figures 5-7 should be placed under the heading "Assessing yield potential/gaps through time for a case study field" in Results section.

Figure 8 and Table 5 should be placed under the heading "Comparison to maximum yield approach" in Results section.

The original article has also been corrected.

Publisher's Note Springer Nature remains neutral with regard to jurisdictional claims in published maps and institutional affiliations.

The original article can be found online at https://doi.org/10.1007/s11119-021-09850-7.

Patrick Filippi

patrick.filippi@sydney.edu.au

1 Faculty of Science, School of Life and Environmental Sciences, Sydney Institute of Agriculture,

The University of Sydney, Sydney, NSW, Australia 